\title{
Study on free amino acid concentrations in umbilical cord blood plasma of newborns from normoglycaemic and gestational diabetes-complicated pregnancies
}

Jarosław Hawryluk', Agnieszka Grafka', Tomasz Gęca², Grzegorz Dzida³, Maciej Łopucki

1 I Chair and Department of Oncological Gynaecology and Gynaecology, Medical University, Lublin, Poland

${ }^{2}$ Chair and Department of Obstetrics and Pathology of Pregnancy, Medical University, Lublin, Poland

${ }^{3}$ Department of Internal Diseases, Medical University, Lublin, Poland

Hawryluk J, Grafka A, Gęca T, Dzida G, Łopucki M. Study on free amino acid concentrations in umbilical cord blood plasma of newborns from normoglycaemic and gestational diabetes-complicated pregnancies. J Pre-Clin Clin Res. 2016; 10(1): 12-22. doi: 10.5604/18982395.1208183

\begin{abstract}
Introduction and objective. Gestational diabetes mellitus is a common disease among pregnant women. The aim of the study was to compare plasma concentrations of 24 amino acids in umbilical cord blood in newborns from normoglycaemic pregnancies versus those complicated by gestational diabetes. The relationship between birth weight and length of newborns and placental concentrations of individual amino acids were also assessed.

Material and methods. The study comprised 76 pregnant women at the gestational age of 37 weeks and more. The control group consisted of 31 women whose $75-\mathrm{g}$ glucose load test excluded gestational diabetes mellitus. The study group encompassed 45 women with diagnosed gestational diabetes mellitus. The placental plasma concentrations of 24 amino acids were determined using ion-exchange chromatography with an automated amino acid analyser.

Results. The concentrations of cysteic acid, aspartic acid, threonine, glutamic acid, cystine, and alpha-aminobutyric acid in umbilical cord blood plasma were higher in the group complicated by gestational diabetes compared to normoglycemic pregnancies; otherwise, concentrations of glutamine, alanine, valine, phenylalanine, lysine and, arginine were lower in the group complicated by gestational diabetes than in the normoglycaemic group.

Conclusions. The results show that despite optimal control of carbohydrate metabolism during gestational diabetes mellitus, there are many abnormalities in the amino acids metabolism. This suggests that research on the effects of amino acids concentration in umbilical cord blood on the foetal development in gestational diabetes-complicated pregnancies should be continued.
\end{abstract}

\section{Key words}

pregnancy, gestational diabetes mellitus, amino acids, umbilical cord blood

\section{INTRODUCTION}

Gestational diabetes mellitus (GDM) is defined as impaired glucose metabolism with onset or first recognition during pregnancy, irrespective of whether disturbances persist or subside after pregnancy [1].

Disturbances in carbohydrate metabolism, commonly accompanied by abnormal lipid metabolism, are most frequently observed in the second half of gestational diabetescomplicated pregnancy. The major disorders in this period include large for gestational age weight (LGA) $>90$ th centile for a given gestational age, and macrosomia defined as absolute foetal weight above $4,200 \mathrm{~g}$. The factors increasing the risk of gestational diabetes are arterial hypertension, polycystic ovary syndrome, glucosuria detected during two independent examinations, hydramnion, glucose intolerance or past diabetes, pregnancy in women over the age of 35 years, and multiparty. The risk factors occur in about $40-60 \%$ of pregnant women with diabetes [1].

Address for correspondence: Agnieszka Grafka, I Chair and Department of Oncological Gynaecology and Gynaecology, Medical University, Staszica 16, 20-081 Lublin, Poland

E-mail: grafkaagnieszka@yahoo.com

Received: 15 March 2016; accepted: 10 April 2016
The incidence of glucose intolerance ranges between 1-14\% of all pregnancies, depending on the population studied and the diagnostic tests employed. Physiologically reduced insulin susceptibility and deterioration of glucose tolerance predominantly develop in the second and third trimester [2].

The most relevant pathogenic factors affecting the development of gestational diabetes are impaired insulin secretion and genetic factors $[2,3]$. Impaired insulin secretion, particularly increased insulin resistance, is associated with pre-pregnancy obesity [2]. Increased insulin resistance is connected with elevated concentrations of many hormones, the action of which is opposite to that of insulin, such as placental lactogen, estrogens, progesterone, cortisol and growth hormone. Moreover, the development of pregnancy induces endocrine and metabolic changes [3]. It is believed that increases in parameters of systolic and diastolic pressure are the first manifestations of impaired carbohydrate metabolism [2, 3, 4]. Many authors confirm the relation between arterial pressure and GDM. Both ailments occurring concomitantly are observed in about $6-8 \%$ of cases [5].

During prenatal life, the developing foetus is completely dependent on the mother's body. The placenta is a barrier between maternal and foetal circulations; oxygen and nutrients diffusion, and waste metabolism products are eliminated through this barrier [6,7]. Metabolites, such as 
glycerol, amino acids, fatty acids and ketone compounds, permeate through the placenta in the amount depending on their concentrations in maternal blood [7]. Therefore, quantitative and qualitative changes occurring in maternal blood induce changes in the concentrations of these substances in foetal blood. The foetus uses them in a manner controlled by its own hormones. Furthermore, the placenta has protective and endocrine function $[3,7]$. In pregnancy complicated by GDM, the placenta is large, villi are variably mature, and the umbilical cord is thick. Such anatomical conditions favour excessive mother-to-foetus permeation of nutrients $[3,7]$.

The transfer through the placental barrier varies according to the type of substance transported (size, solubility, extent of ionization and protein binding), as well as its concentration in the maternal and foetal blood. The simple and facilitated diffusions and active transport are distinguished [6]. Active transport is used for amino acid transfer and its quickest rate is observed between the $16^{\text {th }}-19^{\text {th }}$ gestational week. Some amounts of amino acids are stored in the placenta. Various isomers and forms of amino acids (acidic, alkaline and neutral) permeate through the barrier in different ways. There is an array of systems transporting these compounds (e.g. sodium-dependent and independent) that occur in different barrier layers [6].

Proteins and fats do not permeate the placenta barrier 'in full'; they are re-synthesised in the foetus from amino acids and fatty acids. Amino acids passing from the maternal to foetal blood can be the source of energy but are mainly used for synthesis of proteins. All substrates permeate through the placenta depending on their concentration in the maternal blood. Thus, the foetal nutrition depends on maternal nutritional resources [6].

\section{OBJECTIVE}

The aim of the study was to compare plasma concentrations of 24 amino acids in umbilical cord blood in newborns from normoglycaemic pregnancies versus those complicated by gestational diabetes. The relationship between birth weight and length of newborns and placental concentrations of individual amino acids were also assessed.

\section{MATERIAL AND METHODS}

Patients. The study encompassed 76 women of the Chair and Department of Obstetrics and Pathology of Pregnancy at the Medical University in Lublin, Poland, treated between 2009-2012. The study design was approved by the Bioethics Committee of the Medical University of Lublin.

Pregnant women at the gestational age of 37 weeks and more were included. The gestational age was calculated based on the date of the last menstruation and confirmed by ultrasound examination performed in the first trimester. The normoglycaemic - control group (NG) consisted of 31 women in whom the 75-g glucose load tests carried out between weeks $24-28$ excluded gestational diabetes. The study group (GDM) included 45 women with gestational diabetes, diagnosed by the above test, and otherwise healthy. According to the guidelines of the Polish Diabetic Society, the diagnostic criterion of GDM was glycaemia $\geq 140 \mathrm{mg} /$ dl 2 hours after drinking the glucose solution. When GDM was diagnosed, all patients were put on a diabetic diet; 10 of them required additional insulin therapy. After institution of diet or insulin therapy, patients fulfilled the criteria of diabetes control, i.e. fasting glycaemia $60-95 \mathrm{mg} / \mathrm{dl}$, before a meal $60-105 \mathrm{mg} / \mathrm{dl}, 1 \mathrm{~h}$ after a meal $<120 \mathrm{mg} / \mathrm{dl}$, about 3 a.m. $>60 \mathrm{mg} / \mathrm{dl}, \mathrm{HbAlc}<6.1 \%$, absence of glucosuria and acetonuria.

Biochemical analyses. The study material was umbilical cord blood sampled after delivery and omphalotomy, even before separation and birth of the placenta. Blood samples collected to the test tubes with sodium citrate were centrifuged for $10 \mathrm{~min}$ at $4,000 \mathrm{~g}$. The plasma obtained was distributed to Eppendorf tubes and stored at $-80^{\circ} \mathrm{C}$ until further determinations. The plasma concentrations of free amino acids were determined with the Moore, Stein and Speckman method using an automated amino acid analyser AAA400 (Ingos Prague) [8]; $1 \mathrm{ml}$ of plasma was used for each determination, which was deproteinised by adding $1 \mathrm{ml}$ of $6 \%$ sulphosalicylic acid solution in lithiumcitrate buffer, $\mathrm{pH}$ 2.6. The mixture was left for $20 \mathrm{~min}$. at room temperature. After deproteinisation, each sample was centrifuged for $20 \mathrm{~min}$. at $12,000 \mathrm{~g}$. The supernatant was used to determine the concentrations of the following amino acids: alanine (ALA), arginine (ARG), aspartic acid (ASP), dimer of cysteine (CYS-CYS), cystathionine (CYST), cystine (CIT), glutamine (GLN), glutamic acid (GLU), glycine (GLY), histidine (HIS), isoleucine (ILE), leucine (LEU), lysine (LYS), methionine (MET), phenylalanine (PHE), proline (PRO), serine (SER), taurine (TAU), threonine (THR), tryptophan (TRP), tyrosine (TYR), valine (VAL), cysteic acid (CYSA), and alpha-aminobutyric acid (AABA).

Statistical analysis. The study results were statistically analysed. The values of parameters measured on the quotient scale using a mean, standard deviation, median, upper and lower quartile, with the range of variability provided.

The differences or relationships among the non-measurable parameters were evaluated with contingency tables and the test of uniformity or $\chi^{2}$ test of independence. Since measurable parameters showed a skew distribution evaluated with the Shapiro-Wilk W test or non-uniformity of variance assessed by the Fisher F test, the inter-subgroup differences were analysed using non-parametric tests. Two independent groups were compared by applying the Mann-Whitney $U$ test. Correlations between two measurable parameters were tested using the Spearman's rank correlation coefficient. A $5 \%$ error in drawing conclusions and the level of significance at $\mathrm{p}<0.05$ were assumed.

Statistical analyses were performed using STATISTICA v.8.2 software (StatSoft, Poland).

\section{RESULTS}

Age, height, body weight and BMI gestational diabetescomplicated and nomoglycemic pregnancies were compared (Tab. 1). Statistically significant differences were reported only in relation to height, pre-pregnancy BMI and weight gain during pregnancy.

Data on the place of residence were statistically analysed. Women were divided into 3 groups depending on where they 
Table 1. Statistical analysis on age, height, body weight and BMI of pregnant women complicated by gestational diabetes and normoglycaemia

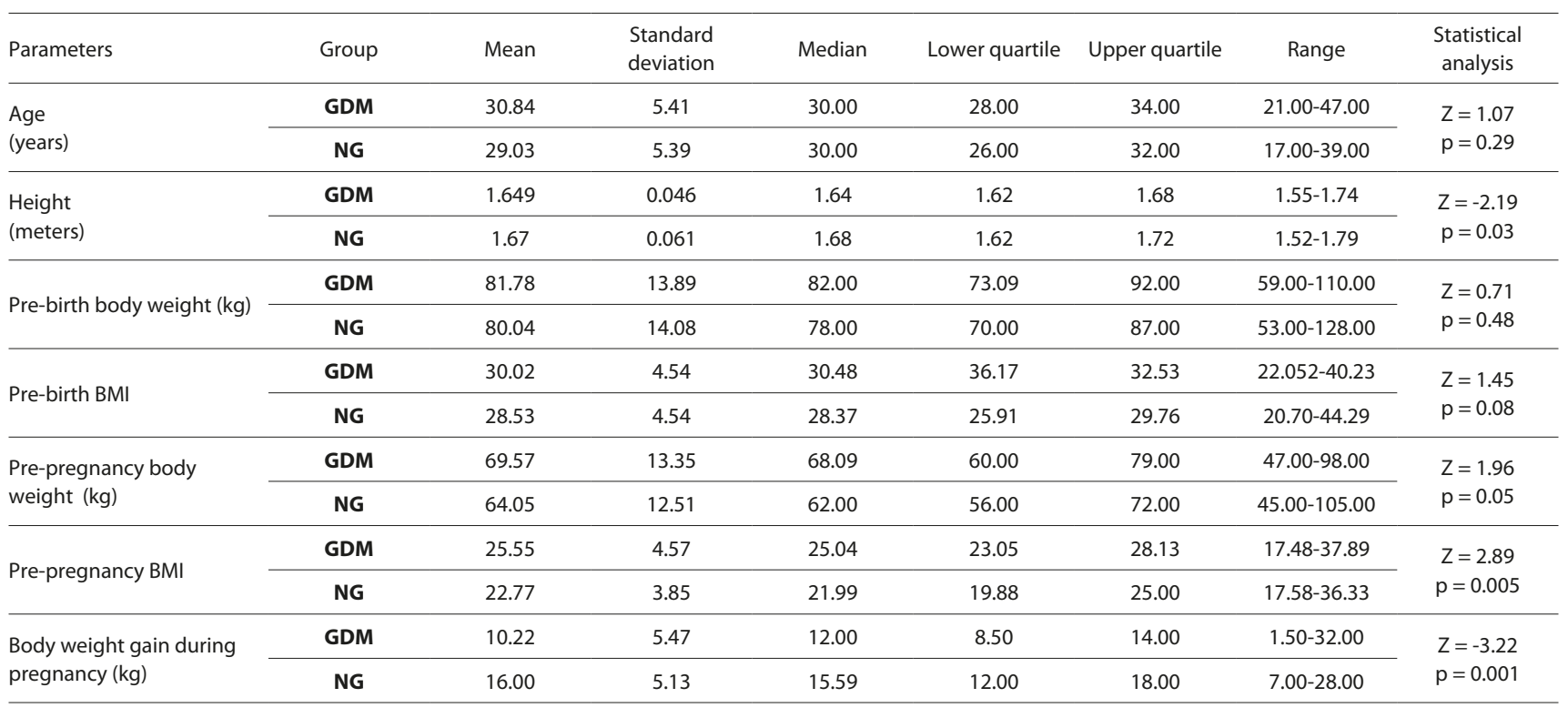

live: village, or town with a population of less than 50,000, or a city with a population of over 50,000. Results were not statistically significant (Tab. 2).

Table 2. Statistical analysis concerning the place of residence of pregnant women

\begin{tabular}{|c|c|c|c|c|}
\hline & & \multicolumn{2}{|c|}{ Group } & \multirow{2}{*}{$\begin{array}{c}\text { Statistical } \\
\text { analysis }\end{array}$} \\
\hline & & GDM & NG & \\
\hline \multirow{3}{*}{$\begin{array}{l}\text { Place of } \\
\text { residence }\end{array}$} & Village & 10 (22.2\%) & $6(19.3 \%)$ & \multirow{3}{*}{$\begin{array}{c}x^{2}=0.42 \\
p=0.81\end{array}$} \\
\hline & $\begin{array}{l}\text { City with less than } \\
50,000 \text { inhabitants }\end{array}$ & $18(40.0 \%)$ & 11 (35.5\%) & \\
\hline & $\begin{array}{l}\text { City with over } \\
50,000 \text { inhabitants }\end{array}$ & 17 (37.8\%) & $14(45.2 \%)$ & \\
\hline
\end{tabular}

Among the analysed amino acids, significantly elevated umbilical cord blood concentrations of CYSA, ASP, THR, GLU, CIT, AABA were found in the gestational diabetes-complicated group, compared to normoglycaemic pregnancies. The concentrations of GLN, ALA, VAL, CYSCYS, PHE, LYS, ARG were lower in the gestational diabetescomplicated group (Tab. 3).

The concentrations of individual amino acids in the group of patients with gestational diabetes and in normoglycemic were statistically analysed according to body weight before pregnancy, BMI before pregnancy, and weight gain during pregnancy.

In the normoglycemic group, the following were observed:

- an increase in body weight before pregnancy was correlated with a decrease in SER ( $\mathrm{p}=0.03 ; \mathrm{R}=-0.39)$, and in the gestational diabetes-complicated group an increase in body weight before pregnancy correlated with a decrease in THR ( $\mathrm{p}=0.04 ; \mathrm{R}=-0.31$ ) (Tab. 4);

- an increase in BMI before pregnancy correlated with a decrease in SER ( $\mathrm{p}=0.03 ; \mathrm{R}=-0.4)$, and in gestational diabetes-complicated group an increase in pre-pregnancy BMI was correlated with a decrease in THR $(\mathrm{p}=0.04$; $\mathrm{R}=-0.30$ ) (Tab. 5).

- an increase in weight gain during pregnancy correlated with an increase in ILE ( $\mathrm{p}=0.005 ; \mathrm{R}=0.49$; Fig. 1), LEU $(\mathrm{p}=0.002 ; \mathrm{R}=0.53$; Fig. 2), PHE ( $\mathrm{p}=0.03 ; \mathrm{R}=0.39$; Fig. 3$)$.

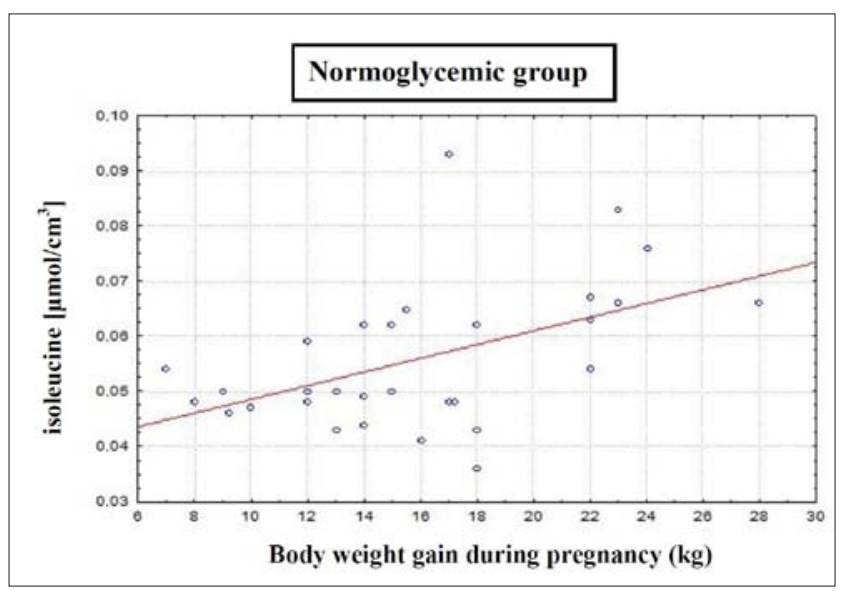

Figure 1. Relationship between isoleucine concentration and body weight gain during pregnancy in normoglycemic women

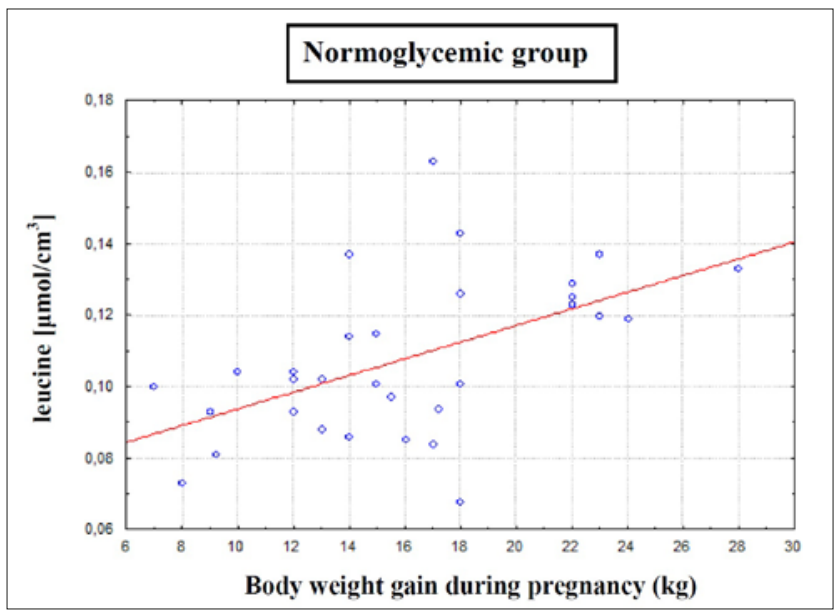

Figure 2. Relationship between leucine concentration and body weight gain during pregnancy in normoglycemic women

Birth weight, length and APGAR score of newborns from gestational diabetes-complicated and normoglycaemic pregnancies were compared (Tab. 6). 
Jarosław Hawryluk, Agnieszka Grafka, Tomasz Gęca, Grzegorz Dzida, Maciej Łopucki. Study on free amino acid concentrations in umbilical cord blood plasma...

Table 3. Umbilical cord blood concentrations of amino acids [ $\left.\mu \mathrm{mol} / \mathrm{cm}^{3}\right]$ in gestational diabetes-complicated (GDM) and normoglycemic (NG) group

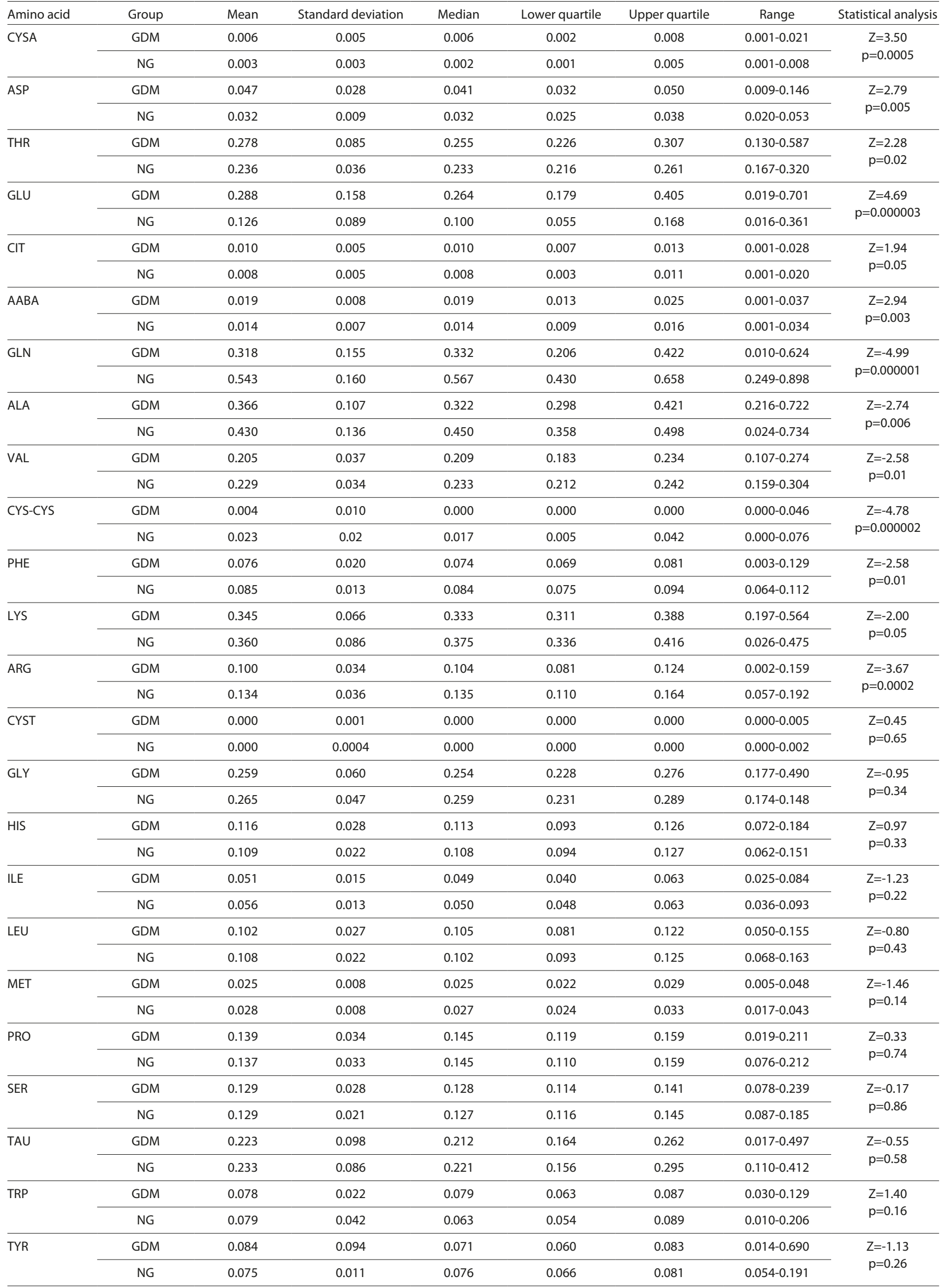


Table 4. Correlation between amino acid concentration and prepregnancy body weight in gestational diabetes-complicated (GDM) and normoglycaemic (NG) group

\begin{tabular}{|c|c|c|c|}
\hline Amino acid \& Pre-pregnancy body weight & Group & $\mathbf{R}$ & $\mathbf{p}$ \\
\hline \multirow{2}{*}{ CYSA } & GDM & 0.23 & 0.13 \\
\hline & NG & 0.001 & 1.00 \\
\hline \multirow{2}{*}{ ASP } & GDM & 0.17 & 0.27 \\
\hline & NG & 0.001 & 0.99 \\
\hline \multirow{2}{*}{ THR } & GDM & -0.31 & 0.04 \\
\hline & NG & -0.02 & 0.91 \\
\hline \multirow{2}{*}{ GLU } & GDM & 0.19 & 0.21 \\
\hline & NG & 0.04 & 0.85 \\
\hline \multirow{2}{*}{ CIT } & GDM & 0.02 & 0.89 \\
\hline & NG & -0.16 & 0.41 \\
\hline \multirow{2}{*}{ AABA } & GDM & -0.12 & 0.44 \\
\hline & NG & 0.08 & 0.68 \\
\hline \multirow{2}{*}{ GLN } & GDM & -0.14 & 0.36 \\
\hline & NG & -0.12 & 0.53 \\
\hline \multirow{2}{*}{ ALA } & GDM & -0.06 & 0.71 \\
\hline & NG & -0.04 & 0.85 \\
\hline \multirow{2}{*}{ VAL } & GDM & 0.09 & 0.58 \\
\hline & NG & 0.13 & 0.49 \\
\hline \multirow{2}{*}{ CYS-CYS } & GDM & 0.03 & 0.83 \\
\hline & NG & -0.03 & 0.87 \\
\hline \multirow{2}{*}{ PHE } & GDM & 0.17 & 0.25 \\
\hline & NG & 0.01 & 0.96 \\
\hline \multirow{2}{*}{ LYS } & GDM & -0.09 & 0.55 \\
\hline & NG & 0.04 & 0.85 \\
\hline \multirow{2}{*}{ ARG } & GDM & -0.04 & 0.78 \\
\hline & NG & -0.23 & 0.25 \\
\hline \multirow{2}{*}{ CYST } & GDM & 0.05 & 0.76 \\
\hline & NG & -0.05 & 0.78 \\
\hline \multirow{2}{*}{ GLY } & GDM & 0.13 & 0.4 \\
\hline & NG & -0.27 & 0.15 \\
\hline \multirow{2}{*}{ HIS } & GDM & -0.24 & 0.11 \\
\hline & NG & -0.06 & 0.74 \\
\hline \multirow{2}{*}{ ILE } & GDM & 0.15 & 0.31 \\
\hline & NG & -0.04 & 0.83 \\
\hline \multirow{2}{*}{ LEU } & GDM & 0.11 & 0.46 \\
\hline & NG & 0.13 & 0.50 \\
\hline \multirow{2}{*}{ MET } & GDM & -0.04 & 0.77 \\
\hline & NG & -0.31 & 0.09 \\
\hline \multirow{2}{*}{ PRO } & GDM & -0.10 & 0.52 \\
\hline & NG & -0.21 & 0.25 \\
\hline \multirow{2}{*}{ SER } & GDM & 0.12 & 0.44 \\
\hline & NG & -0.39 & 0.03 \\
\hline \multirow{2}{*}{ TAU } & GDM & 0.09 & 0.56 \\
\hline & NG & -0.11 & 0.56 \\
\hline \multirow{2}{*}{ TRP } & GDM & 0.22 & 0.16 \\
\hline & NG & 0.13 & 0.49 \\
\hline TYP & GDM & 0.02 & 0.87 \\
\hline (1) & NG & -0.07 & 0.70 \\
\hline
\end{tabular}

Table 5. Correlation between amino acid concentration and prepregnancy BMI in the gestational diabetes-complicated (GDM) and normoglycemic (NG) group

\begin{tabular}{|c|c|c|c|}
\hline Amino acid \& pre-pregnancy BMI & Group & $\mathbf{R}$ & $\mathbf{p}$ \\
\hline \multirow{2}{*}{ CYSA } & GDM & 0.24 & 0.11 \\
\hline & NG & -0.07 & 0.71 \\
\hline \multirow{2}{*}{ ASP } & GDM & 0.19 & 0.22 \\
\hline & NG & -0.04 & 0.84 \\
\hline \multirow{2}{*}{ THR } & GDM & -0.30 & 0.04 \\
\hline & NG & -0.06 & 0.76 \\
\hline \multirow{2}{*}{ GLU } & GDM & 0.18 & 0.25 \\
\hline & NG & 0.12 & 0.50 \\
\hline \multirow{2}{*}{ CIT } & GDM & 0.007 & 0.97 \\
\hline & NG & -0.11 & 0.56 \\
\hline \multirow{2}{*}{ AABA } & GDM & -0.05 & 0.73 \\
\hline & NG & 0.11 & 0.58 \\
\hline \multirow{2}{*}{ GLN } & GDM & -0.08 & 0.59 \\
\hline & NG & -0.21 & 0.25 \\
\hline \multirow{2}{*}{ ALA } & GDM & 0.03 & 0.83 \\
\hline & NG & -0.31 & 0.09 \\
\hline \multirow{2}{*}{ VAL } & GDM & 0.14 & 0.36 \\
\hline & NG & 0.09 & 0.63 \\
\hline \multirow{2}{*}{ CYS-CYS } & GDM & -0.02 & 0.88 \\
\hline & NG & -0.05 & 0.81 \\
\hline \multirow{2}{*}{ PHE } & GDM & 0.19 & 0.22 \\
\hline & NG & -0.09 & 0.62 \\
\hline \multirow{2}{*}{ LYS } & GDM & -0.05 & 0.76 \\
\hline & NG & -0.05 & 0.79 \\
\hline \multirow{2}{*}{ ARG } & GDM & 0.009 & 0.95 \\
\hline & NG & -0.19 & 0.34 \\
\hline \multirow{2}{*}{ CYST } & GDM & 0.06 & 0.68 \\
\hline & NG & 0.04 & 0.81 \\
\hline \multirow{2}{*}{ GLY } & GDM & 0.18 & 0.24 \\
\hline & NG & -0.26 & 0.16 \\
\hline \multirow{2}{*}{ HIS } & GDM & -0.21 & 0.16 \\
\hline & NG & -0.21 & 0.26 \\
\hline \multirow{2}{*}{ ILE } & GDM & 0.19 & 0.22 \\
\hline & NG & -0.04 & 0.82 \\
\hline \multirow{2}{*}{ LEU } & GDM & 0.15 & 0.32 \\
\hline & NG & 0.10 & 0.60 \\
\hline \multirow{2}{*}{ MET } & GDM & -0.08 & 0.61 \\
\hline & NG & -0.36 & 0.05 \\
\hline \multirow{2}{*}{ PRO } & GDM & -0.04 & 0.81 \\
\hline & NG & -0.25 & 0.17 \\
\hline \multirow{2}{*}{ SER } & GDM & 0.15 & 0.31 \\
\hline & NG & -0.40 & 0.03 \\
\hline \multirow{2}{*}{ TAU } & GDM & 0.08 & 0.61 \\
\hline & NG & -0.14 & 0.46 \\
\hline \multirow{2}{*}{ TRP } & GDM & 0.26 & 0.09 \\
\hline & NG & 0.07 & 0.71 \\
\hline & GDM & 0.03 & 0.86 \\
\hline n & NG & -0.10 & 0.59 \\
\hline
\end{tabular}


Table 6. Analysis of birth weight, length and APGAR score of newborns in the gestational diabetes-complicated (GDM) and normoglycaemic (NG) group

\begin{tabular}{|c|c|c|c|c|c|c|c|c|}
\hline Parameters & Group & Mean & Standard deviation & Median & Lower quartile & Upper quartile & Range & Statistical analysis \\
\hline \multirow{2}{*}{ Birth weight } & GDM & 3295.33 & 696.11 & 3320.00 & 3070.00 & 3800.00 & $1390-4850$ & \multirow{2}{*}{$\begin{array}{l}Z=-0.76 \\
p=0.45\end{array}$} \\
\hline & NG & 3410.16 & 386.29 & 3505.00 & 3110.00 & 3660.00 & $2610-4200$ & \\
\hline \multirow{2}{*}{ Body length } & GDM & 53.87 & 4.07 & 54.50 & 51.50 & 57.00 & $43-60$ & \multirow{2}{*}{$\begin{array}{l}Z=1.11 \\
p=0.27\end{array}$} \\
\hline & NG & 53.52 & 2.48 & 54.00 & 51.00 & 55.00 & $49-58$ & \\
\hline \multirow{2}{*}{ APGAR } & GDM & 9.400 & 1.156 & 10.00 & 9.00 & 10.00 & $6-10$ & \multirow{2}{*}{$\begin{array}{l}Z=-0.86 \\
p=0.39\end{array}$} \\
\hline & NG & 9.774 & 0.457 & 10.00 & 10.00 & 10.00 & $8-10$ & \\
\hline
\end{tabular}

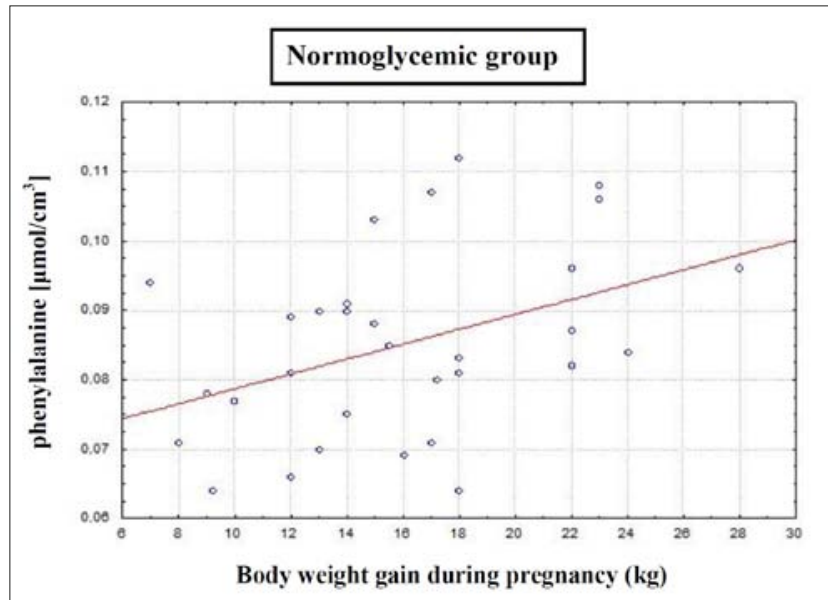

Figure 3. Relationship between phenylalanine concentration and body weight gain during pregnancy in normoglycemic women

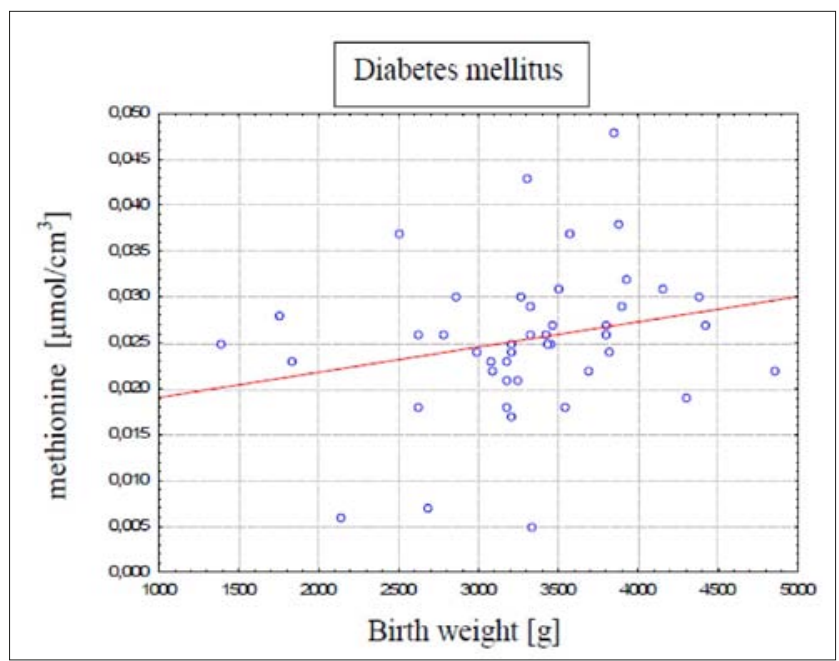

Figure 4. Relationship between methionine concentration and birth weight in gestational diabetes-complicated pregnant women.

The concentrations of individual amino acids in the group of patients with gestational diabetes and in normoglycaemic were statistically analysed according to birth weight. Statistically significant differences were observed in MET $(\mathrm{p}=0.04 ; \mathrm{R}=0.31$ - positive correlation - in the group of pregnant women with diabetes, the higher the birth weight the higher the MET; Fig. 4) and CYST concentrations $(\mathrm{p}=0.00002 ; \mathrm{R}=-0.42$ - negative correlation - in the normoglycaemic group, the higher the birth weight, the lower the CYST concentration).

Furthermore, the relationship between concentrations of individual amino acids in gestational diabetes-complicated and normoglycaemic group was analysed according to the newborn body length. In the gestational diabetes-complicated group, statistically significant differences were observed in $\operatorname{AABA}(\mathrm{p}=0.04 ; \mathrm{R}=-0.33)$.

The concentrations of individual amino acids in the group of patients with gestational diabetes and in normoglycaemic were statistically analysed according to the APGAR score.

In the normoglycaemic group, an increase in APGAR score was correlated with a decrease in LEU ( $\mathrm{p}=0.03 ; \mathrm{R}=-0.38)$, and in gestational diabetes-complicated group an increase in APGAR score was correlated with an increase in TRP $(\mathrm{p}=0.04 ; \mathrm{R}=0.31)$.

\section{DISCUSSION}

Depending on the population studied, diabetes mellitus during pregnancy occurs in from $1-14 \%$ of all pregnancies [2]. In Poland, the incidence of diabetes mellitus in pregnancy is $3-5 \%, 80-85 \%$ of them is gestational diabetes mellitus (GDM) [3].

According to the obtained results, there is a close to statistical significance difference $(\mathrm{p}=0.05)$ in pre-pregnancy body weight between normoglycaemic and GDM women. Thist results in a highly statistically significant pre-pregnancy BMI ( $p=0.005)$. Obesity is often associated with an unhealthy lifestyle and bad eating habits, learned from the family home. In addition, the occurrence of diabetes in some cases determines genetic predisposition [9].

The presented study shows a statistically significant difference in body weight gain during pregnancy between normoglycaemic and GDM women $(\mathrm{p}=0.001)$. In assessing pre-pregnancy body weight it can be assumed that most of the women participating in the study followed the recommendations of US National Academy of Science [10].

Both pre-birth body weight and BMI do not reach a significant difference between the groups. Griss et al. [11] obtain similar results regarding body weight. However, women with GDM compared to normoglycemic subjects have higher BMI.

The correlation between the amino acids concentration (group with GDM and normoglycaemic) and pre-pregnancy body weight and BMI was assessed. In the normoglycaemic group, statistically significant results for pre-pregnancy body weight were obtained for SER $(p=0.03 ; R=-0.39)$. This is associated with a significant difference in the concentration of SER in the normoglycaemic group, depending on prepregnancy BMI $(\mathrm{p}=0.03 ; \mathrm{R}=-0.40)$.

Among the pregnant women with GDM, a statistically significant correlation $(\mathrm{p}=0.04 ; \mathrm{R}=-0.31$ ) was obtained for THR concentration and pre-pregnancy body weight. This is 
associated with a statistically significant difference in THR concentration in GDM group, depending on pre-pregnancy BMI ( $\mathrm{p}=0.04 ; \mathrm{R}=-0.30)$.

It can be assumed that women with a smaller amount of body fat have higher SER and THR concentration in umbilical cord blood, which may be related with an increased muscle mass. In the literature, no results were found confirming the above observations.

Kamaura et al. [12] have presented a correlation between amino acid concentration and BMI and the metabolic syndrome, but in groups without pregnant women. They examined amino acid concentrations in people with metabolic syndrome compared to healthy controls. In those with metabolic syndrome, the aromatic amino acids concentration was significantly higher than in control group. Simultaneously, the authors claimed that after application of a healthy lifestyle and diet, aromatic amino acids concentration decreased.

The correlation between amino acids (women with GDM and normoglycaemic) concentration and body weight gain during pregnancy was assessed. There was a direct proportional relationship: the larger the weight gain, the higher the concentration of ILE, LEU and PHE in normoglycaemic pregnancies. In previously published work, the researchers did not examine such a correlation. Elevated PHE concentration in metabolic syndrome is also demonstrated by Kamaura et al. [12]. This may suggest that a significant body weight gain during pregnancy causes similar disturbances to those in metabolic syndrome.

Tai et al. [13] demonstrate correlation between insulin resistance and a higher level of all the branched-chain amino acids (LEU, ILE, VAL).

In the situation of prolonged maternal hyperglycemia, the developing foetus is also exposed to high glucose concentrations. Oversupply glucose to the foetus causes the child's developing body to store it as fat tissue and lasts a long time. This is connected with the described in the literature excessive insulin secretion by the foetus: maternal hyperglyacemia leads to reactive hyperinsulinaemia which enhances tissue growth, and is one of the main causes of macrosomia $[2,14]$. Persistent hyperglycaemia in the mother increases the risk of birth defects and increases in proportion to the increase of glucose values in blood [2].

In the current study, the mean body weight of a newborn was 3,295.33g in the group with GDM, and 3,410.16g in the normoglycaemic women. The results were not significant $(\mathrm{p}=0.45)$. The obtained results are not consistent with the available data in the literature. The authors noted an increased body weight of newborns from pregnancies with GDM, compared to newborns from normoglycaemic pregnancies $[15,16]$. According to Szymańska et al. [17], the incidence of foetal hypertrophy is $10 \%$. No significant differences in body weight of newborns between GDM and normoglycaemic group can confirm the important role of other factors not included in this study. Jędrzejowska et al. [18] emphasize the role of non-gestational diabetes factors that may have an influence on the risk of complications during pregnancy and delivery, such as overweight and obesity before pregnancy.

Intrauterine foetal growth is conditioned by constitutionalgenetic factors, efficiency of the placental-foetal unit, and metabolic-hormonal changes occurring in pregnant women. The basic building substances for the developing foetus are amino acids, fatty acids and glucose. Maternal hyperglycaemia and foetal hyperinsulinism are the key factors leading to excessive birth weight [19].

The factor responsible for excessive foetal growth at normal maternal glycaemia is likely to be impaired amino acid metabolism [20]. The available data demonstrate that in women with GDM the metabolism of amino acids is not normal. Reduced insulin resistance induces excessive delivery of amino acids to the placenta and foetus. It has been shown that in foetal life, the secretion of insulin by beta cells of pancreatic islets is more strongly stimulated by amino acids than by glucose $[21,22,23,24]$.

The studies regarding the relationship between amino acid concentrations in the umbilical blood plasma and birth weight in diabetic and normoglycaemic mothers did not reveal a correlation between the degree of glycaemia control and plasma amino acid profile. According to the findings of the current study, only concentrations of MET and CYST were correlated with birth weight. The birth weight grew for both increasing MET concentration $(\mathrm{p}=0.04$; $\mathrm{R}=$ 0.31 in the gestational diabetes-complicated group), and decreasing CYST concentration $(\mathrm{p}=0.00002 ; \mathrm{R}=-0.42$ in the normoglycaemic group). Metzger [25] did not confirm these results for MET. This allows the hypothesis that substrates other than glucose, the concentrations of which are insulindependent, also affect the foetal weight. Amino acids, the basic building material of the foetus, were shown to be actively transported depending on the placental haemodynamic status [19]. Moreover, normalisation of amino acid and lipid metabolism was shown to be likely to improve perinatal results observed under strict glycaemia control [26].

McClain et al. [27] do not confirm the correlation observed in the presented study, but do show a correlation between ARG concentration and body weight of newborns. The study was conducted on a group of pregnant women at 25 weeks gestation, and not in the perinatal period, so this could have resulted in the difference. Both McClain et al. [27] and Metzger [25] demonstrate a correlation between body weight of newborns and TYR concentration. This is not confirmed in the presented study.

Despite the diet and insulin therapy, macrosomia and its complications are still observed in newborns of mothers with GDM [24]. In the current study group with controlled diabetes, there were no statistically significant increases in birth weight. The effects of carbohydrate-low diets used during pregnancy were reflected in the $115 \mathrm{~g}$ lower increase in birth weight, compared to the normoglycaemic group, despite increased pre-pregnancy BMI in women with GDM. This suggests that research on the effects of body weight and BMI before pregnancy and diets on foetal development should be continued.

The correlation between amino acids concentration and APGAR score was assessed. The bigger the APGAR score, the lower the LEU concentration in normoglycaemic pregnant women, and the bigger the APGAR score, the higher the TRP concentration in gestational diabetes-complicated women. In the literature, there are no papers on this issue.

Pregnancy markedly affects the metabolism of carbohydrates, proteins and fats. The relationship between the concentration of glucose and amino acids has not been fully elucidated, particularly in cases of gestational diabetes mellitus. The literature contains only a few papers regarding this topic [28]. In pregnant women, elevated fasting concentrations of insulin are observed; in the second half of 
pregnancy, such elevated levels are also found after meals. Nevertheless, post-meal glycaemia increases [22, 29]. This clinical picture evidences increasing insulin resistance, which was confirmed in direct determinations [29]. The cause of such a phenomenon in pregnant women has not been clearly explained. Insulin resistance in pregnancy is of a pre- and post-receptor nature. Shao et al. [30] indicate that yhis is predominantly a post-receptor event - impaired expression of insulin receptor 1 (IR-1) and disturbed signalling pathway of this receptor during intracellular metabolic activation. Wender-Ożegowska et al. [14] suggest that the reduced effects of insulin in pregnancy are also caused by impaired activity of glucose transporter GLUT-4.

Numerous studies have been conducted on protein metabolism and on the mode of amino acid transfer from mother to foetus, with good reviews about these mechanisms available in the literature [31, 32, 33, 34]. Unfortunately, there are only a few reports on the differences in the concentration of amino acids in umbilical cord blood plasma between normoglycaemic pregnancies and those complicated by gestational diabetes.

As far as protein metabolism is concerned, the concentrations of the majority of amino acids in maternal serum are lower in pregnancy than in the post-delivery period. Some results have demonstrated a decrease in serum alpha-amino-itrogen, from $3.0 \mathrm{mmol} / 1$ in non-pregnant women to $2.3 \mathrm{mmol} / \mathrm{l}$ during pregnancy. Other findings have revealed substantially reduced serum concentrations of glucogenic amino acids (ALA, SER, GLN, GLU) during fasting in pregnant women. Despite the differences in serum insulin concentrations, the basic and post-meal serum concentrations of branched-chain amino acids are comparable in women with and without insulin-dependent gestational diabetes during all trimesters of pregnancy [19]. The presented study confirmed reduced umbilical blood concentrations of ALA and GLN in pregnant women with gestational diabetes.

Cetin et al. [28] conducted a study which compared the amino acid concentrations from umbilical cord blood of normoglycaemic and gestational diabetes-complicated pregnancies. They observed a significant increase for valine, methionine, phenylalanine, isoleucine, leucine, ornithine, glutamate, proline, alanine from gestational diabetescomplicated pregnancies, whereas glutamine was significantly decreased. The study was conducted on a small group of patients - 16 normoglycemic and 17 gestational diabetescomplicated women. The current study was characterized by larger groups: 31 and 45 women, respectively, and demonstrated completely different results. Statistically lower concentrations of phenyloalanine, alanine and valine in gestational diabetescomplicated women were found. Otherwise, there were no statistically significant differences in methionine, isoleucine, leucine and proline between both groups. Only the results concerning glutamine were similar to those obtained by Cetin et al. [28]. These discrepancies in results suggest that research on this subject should be continued.

In controlled gestational diabetes, analysis of amino acid concentrations in the umbilical blood showed significantly elevated levels of exo- and endogenous amino acids in serum of venous and arterial blood [28].

Pappa et al. [35] present in pregnant women between $30-33$ weeks of gestation, a significantly higher $(\mathrm{p}<0.001)$ concentration of GLY in the normoglycaemic pregnant women, compared to pregnant women with GDM. This is not confirmed in the presented study. This can result from the fact that the current study was conducted in later stages of pregnancy (umbilical cord blood) than in the cited study. Butte et al. [23] also do not confirm the results obtained by Pappa et al.

Freyse et al. [36] and Meynial-Denis et al. [37] report higher levels of ALA in animals with diabetes. This level is not confirmed by the current research. Pappa et al. [35] obtained results that coincided with the presented results. ALA concentration was significantly higher in normoglycaemic women compared to those with GDM ( $p=0.01)$. The beneficial effect of high ALA concentrations on glucagon secretion in hypoglycaemia was demonstrated by Porcellati et al. [38], which suggests that higher concentrations of amino acids may be advantageous in diabetes, and have protective function in the case of hypoglycaemia.

Leucine, isoleucine, and valine possess a similar structure with a branched-chain residue, and are therefore referred to as BCAAs. Lee et al. confirmed that plasma BCAAs are associated with incident diabetes and underlying metabolic abnormalities [39].

The presented study examined the branched-chain amino acids: VAL, LEU and ILE. No statistically important differences between normoglycaemic women and those with GDM were reported for ILE and LEU, only VAL results were significant $(\mathrm{p}=0.01)$. Meynial-Denis et al. [37] showed an increased level of LEU transformation into ALA in skeletal muscle in diabetes. They also observed an increase in ALA concentration, as well as an increased rate of metabolism of these amino acids. Reece et al. [40], however, obtained different results. Research on diabetic pregnant women treated with insulin injections (multiple injections or infusion pump) showed that in correctly balanced diabetes the ALA concentration and branched-chain amino acids is the same as in the normoglycaemic group.

No differences in branched-chain amino acids concentration between normoglycaemic and gestational diabetes-complicated pregnant women were reported by Pappa et al. [35]. In contrast, Butte et al. [23] present significant differences in the concentration of branchedchain amino acids between normoglyceamic and gestationaldiabetes complicated women: $\mathrm{p}=0.0008$ for ILE, $\mathrm{p}=0.002$ for LEU and 0.004 for VAL. In all cases, concentrations were higher in the group with GDM.

In the presented study, a statistically higher THR concentration was found in gestational-diabetes complicated women. Jóźwik et al. [41] show that at the end of ovine pregnancy, a high concentrations of branched-chain amino acids caused the reduced transport of MET and THR through the placenta. This could explain the lower THR concentration in umbilical cord blood in women with GDM obtained in the current study. Kamaura et al. [12] presented a higher THR concentration in people with metabolic syndrome, but the level of THR decreased after the application of a healthy lifestyle and diet. This suggests the normalization of the level of amino acids after delivery. This the issue requires further investigation. Based on theresults by Kamaura et al., it can be concluded that pregnant women with GDM have similar metabolic disorders.

Between the group with GDM and the normoglyacemic group, a statistically significant difference in CYS-CYS concentration $(p=0.000002)$ was reported (higher in 
normoglycaemic group). Tai et al. [13] and Pappa et al. [35] do not confirm the presented observations. The different results were probably caused by the correct metabolic control in the pregnant women participating in the presented study. Butte et al. [23] demonstrated higher CYS-CYS concentration in diabetic pregnant women $(p=0.006)$. No significant differences in MET concentration between normoglycaemic and GDM groups were reported in either the presented study and the study by Butte et al. [23]. In contrast, Cetin et al. [28] and Pappa et al. [35] presented increased levels of MET in umbilical cord blood from mothers with GDM.

The current study shows a higher concentration of GLN in normoglycaemic and a higher GLU concentration in women with GDM. Similar results for GLU were presented by Kamaura et al. [12] who reported that among people with a metabolic syndrome, the level of GLN and GLU was significantly higher than in the control group. Simultaneously, it decreased after application of a healthy lifestyle and diet. Furthermore, Garcia et al. [42] showed that a higher level of GLN causes faster normalization of blood glucose after episodes of hypoglycaemia in rats. Reimann et al. [43] also suggest that GLN has a beneficial effect in the treatment of obesity and diabetes. GLN, which is stronger than glucose or other amino acids, stimulates the secretion of glucagon-like peptide-1 (Glucagon-like peptide-1 GLP-1) and peptide YY (Peptide YY - PYY).

In contrast to Cetin et al. [28] and Pappa et al. [35], the current study shows a significant difference in the concentration of ASP $(p=0.005)$ and ARG $(p=0.0002)$. Cetin et al. [28] and Pappa et al. [35] demonstrate no significant differences between the group of pregnant women with GDM and the normoglycemic group in the case of LYS and HIS, which is confirmed by the current study. In contrast to the cited references, Butte et al. [23] present different results. They observed higher levels of LYS in pregnant women with GDM compared to normoglycaemic pregnant women.

Whereas the presented study demonstrates a significant difference in PHE concentration between the group with GDM and normoglycaemic woman ( $\mathrm{p}=0.01$ higher in normoglycaemic mothers), Cetin et al. [28] do not confirm this observation. Pappa et al. [35], in a group of pregnant between 30-33 weeks of gestation, do not show a statistically significant difference in PHE levels between the groups.

In the presented study, no significant differences were found in the concentration of TYR, TRP, PRO and TAU, between pregnant women with GDM and normoglycaemic women. Cetin et al. [28] confirm results for TYR, and Pappa et al. [35] for PRO. In contrast, Cetin et al. [28] observed increased levels of PRO in umbilical cord blood from mothers with GDM. Franconi, et al. [44] show that diabetic patients treated with insulin have a lower TAU concentration compared to healthy individuals. The amino acids concentration in umbilical cord blood depends on the concentration of amino acids in maternal blood and efficient transport through the placenta. Transplacental transport consists of 3 main stages: 1) amino acids uptake from maternal circulation through membrane micro blood vessels;

2) transport through cytoplasm of the trophoblast;

3) transfer of amino acids through the basement membrane to umbilical cord blood [45].

There are many factors that affect the transplacental transport of amino acids, e.g. surface of the placenta, maternal and foetal blood flow, perfusion of the placenta, ion gradient, placental metabolism, energy supplies, circulating hormones and drugs [46]. The amino acid concentration is higher in foetal than in maternal blood, and the system of their transportation was shown both in the micro blood vessels and the basement membrane of placenta $[28,45]$. The increased activity of amino acid transport systems may result in macrosomia [28].

In addition to the transport function, the syncytiotrophoblast is also involved in amino acids metabolism [45, 46]. Furthermore, McBride et al. [47] indicate that genetic factors and current nutritional status have an influence on amino acids concentration. The final results, however, are inconclusive, and in assessing the levels of amino acids, both the genetic and environmental factors should be taken into consideration.

Shikata et al. [48] prove that the amino acids concentration is variable and depends on the general state of the organism and diet. According that study, LYS has an influence on serum concentration of all amino acids.

Haase et al. [49] suggest that a low protein diet during pregnancy results in reduction in the mass of beta cells in newborns, and as a result, it may cause difficulties in adaptation of the organism to the typical contemporary sedentary lifestyle and excess in food intake.

The authors of several studies suggest that the metabolic rates of proteins are elevated in pregnant women with GDM compared to normoglycaemic women $[50,51]$. The levels of amino acids in the compared groups did not always exhibit such a relationship. Many researchers, including Cetin [28], Pappa [35] and Butte [23], obtained different results for different amino acids. Butte et al. [23] claim that the concentration of amino acids in blood does not fully reflect the metabolism of proteins and amino acids. Perhaps they are not appropriate for assessing the concentration of amino acids throughout the body.

In the light of available results presented in current literature, it seems appropriate to state that amino acids metabolism in pregnancy is still the focus of attention in many research centres.

Evaluation of amino acid concentration is only 'the tip of the iceberg' of disturbed protein metabolism in pregnancy complicated by diabetes.

\section{CONCLUSIONS}

The results obtained provide a basis to conclude that, despite optimal control of carbohydrate metabolism during pregnancy with GDM, abnormalities in amino acids metabolism are still present.

Women with diagnosed gestational diabetes mellitus ought to be under specialist obstetric-diabetological care. The success in diabetes treatment relies on the close cooperation of physicians, midwives and dieticians, who should clearly and comprehensively inform their patients about the relevant role of proper diet, physical exercises or insulin, if needed.

This suggests that research on the effects of concentration of amino acids in umbilical cord blood on the foetal development in gestational diabetes-complicated pregnancies should be continued, and the future introduction of determinations of selected amino acids into clinical practice for diagnostic purposes and monitoring of diabetes therapy should be taken into consideration. 


\section{REFERENCES}

1. Polish Gyneacological Society Standards of Medical Care in management of women with diabetes. Ginekol Pol. 2011; 82(6): 474-479.

2.Murthy EK, Pavlić-Renar I, Metelko Ž. Diabetes and pregnancy. Diabetol Croatica. 2002; 31-3: 131-146.

3. Hawryluk J, Grafka A, Gęca T, Łopucki M. Gestational diabetes in the light of current literature. Pol Merkur Lek. 2015; 38(228): 344-347.

4. Mahmud M, Mazza D. Preconception care of women with diabetes: a review of current guideline recommendations. BMC Women's Health 2010; 10(5): 1-7.

5.Ulman-Włodarz I, Salomon-Perzyńska M. Cukrzyca ciążowa i nadciśnienie w ciąży - współczesne postępowanie. W: Zespó metaboliczny u kobiet - problem interdyscyplinarny (red.). LeszczyńskaGorzelak B i Oleszczuk J. Oddział Lubelski Pol Tow Medycyny Perinatalnej. Lublin. 2010; 195-202 (in Polish).

6. Avagliano L, Garò Ch, Marconi AM. Placental Amino Acids Transport in Intrauterine Growth Restriction. J Pregnancy. 2012; 972562: 1-6.

7. Latendresse G, Founds S. The fascinating and complex role of the placenta in pregnancy and fetal well-being. J Midwifery Womens Health. 2015; 60(4): 360-370.

8. Moore S, Spackman DH, Stein WH. Chromatography of amino acids on sulfonated polystyrene resins. An improved system. Anal Chem. 1958; 30(7): 1185-1190.

9. Hyttinen V, Kaprio J, Kinnunen L, Kosekenvuo M, Tuomilehto J. Genetic liability of type 1 diabetes and the onset age among 22,650 young Finnish twin pairs: a nationwide follow-up study. Diabetes. 2003; 52(4): 1052-1055.

10. Krentz AJ. Cukrzyca. Med Prakt. Kraków, 2001 (in Polish).

11. Grissa O, Yessoufou A, Mrisak I, Hichami A, Amoussou-Guenou D, Grissa A, et al. Growth factor concentrations and their placental mRNA expression are modulated in gestational diabetes mellitus: possible interactions with macrosomia. BMC Pregnancy and Childbirth. 2010; 10:7. doi:10.1186/1471-2393-10-7.

12. Kamaura M, Nishijima K, Takahashi M, Ando T, Mizushima S Tochikubo O. Lifestyle modification in metabolic syndrome and associated changes in plasma amino acid profiles. Circ J. 2010; 74(11): 2434-2440.

13. Tai ES, Tan ML, Stevens RD, Low YL, Muehlbauer MJ, Goh DL, et al. Insulin resistance is associated with a metabolic profile of altered protein metabolism in Chinese and Asian-Indian men. Diabetologia. 2010; 53(4): 757-767

14. Wender-Ożegowska E, Sporna M, Zawiejska A. Cukrzyca ciążowa (GDM) - patomechanizm i konsekwencje kliniczne. Terapia. 2007; 2 : 24-30 (in Polish).

15. Kinalski M, Śledziewski A, Majkowicz-Młynarczyk A, Kuźmicki M. Ciąża powikłana cukrzycą. Med Wieku Rozw. 2004; 8(3) część II: 691-701 (in Polish).

16. Schaefer-Graf UM, Kjos SL, Kilavus O, Plagemann A, Brauer M, Dudenhausen JW, Vetter K. Determinants of fetal growth at different periods of pregnancies complicated by gestational diabetes mellitus or impaired glucose tolerance. Diabetes Care. 2003; 26(1): 193-198.

17. Szymańska M, Bomba-Opoń DA, Celińska AM, Wielgoś M. Diagnostic of gestational diabetes mellitus and the prevalence of LGA (Large for Gestational Age). Ginekol Pol. 2007; 78(3): 177-181.

18. Jędrzejowska E, Wilczyński J, Podciechowski L. Evaluation of the prognostic value of chosen maternal risk factors of complications existing among newborns of GDM mothers. Ginekol Pol. 2000; 70(10): 689-699.

19.Zamłyński J, Olejek A, Więcek A, Mańka G, Chudek J, Bodzek P, Damasiewicz-Bodzek A. The infl uence of metabolic changes on intrauterine fetal growth in normal gestation and gestation complicated by diabetes. Postępy Hig Med Dośw. 2005; 59: 490-495.

20. Hod M, Yogev Y. Goals of metabolic management of gestational diabetes: is it all about the sugar? Diabetes Care. 2007; 30Suppl2: S180-S187.

21.Sertkaya AC, Kafkasli A, Turkcuoglu I, Karabulut AB. Asymmetric dimethylarginine level in hyperglycemic gestation. Endocrine. 2011; 40(2): 237-242.

22. Hay WW. Placental-fetal glucose exchange and fetal glucose metabolism. Trans Am Clin Climatol Assoc. 2006; 117: 321-340.

23. Butte NF, Hsu HW, Thotathuchery M, Wong WW, Khoury J, Reeds P. Protein Metabolism in Insulin-Treated Gestational Diabetes. Diabetes Care. 1999; 22(5): 806-811.

24. Stenninger E, Achollin J, Aman J. Neonatal macrosomia and hypoglycaemia in children of mothers with insulin-treated gestational diabetes mellitus. Acta Paediatr Scand. 1991; 80(11): 1014-1018.
25. Metzger BE. Biphasic effects of maternal metabolism on fetal growth quintessential expression of fuel-mediated teratogenesis. Diabetes. 1991; 40(Suppl2): 99-105.

26. Kinalski M, Śledziewski A, Telejko B, Kowalska I, Kretowski A, Zarzycki W, Kinalska I. Lipid peroxidation, antioxidant defence and acid-base status in cord blood at birth: the influence of diabetes. Horm Metab Res. 2001; 33(4): 227-231.

27. McClain PE, Metcoff J, Crosby WM, Costiloe JP. Relationship of maternal amino acid profiles at 25 weeks of gestation to fetal growth. Am J Clin Nutr. 1978; 31(3): 401-407.

28. Cetin I, de Santis MS, Taricco E, Radaelli T, Teng C, Ronzoni S, et al. Maternal and fetal amino acid concentrations in normal pregnancies and in pregnancies with gestational diabetes mellitus. Am J Obstet Gynecol. 2005; 192(2): 610-617.

29. Catalano PM, Tyzbir ED, Wolfe RR, Roman NM, Amini SB, Sims EA. Longitudinal changes in basal hepatic glucose production and suppression during insulin infusion in normal pregnant women. Am J Obstet Gynecol. 1992; 167(4Pt1): 913-919.

30. Shao J, Catalano PM, Yamashita H, Ruyter I, Smith S, Youngren J, Friedman JE. Decreased insulin receptor tyrosine kinase activity and plasma cell membrane glycoprotein-1 overexpression in skeletal muscle from obese women with gestational diabetes mellitus (GDM): evidence for increased serine/threonine phosphorylation in pregnancy and GDM. Diabetes. 2000; 49(4): 603-610.

31. Cariappa R, Heath-Monnig E, Smith $\mathrm{CH}$. Isoforms of amino acid transporters in placental syncytiotrophoblast: plasma membrane localization and potential role in maternal/fetal transport. Placenta 2003; 24(7): 713-726.

32. Józwik M, Teng C, Wilkening RB, Meschia G, Battaglia FC. Reciprocal inhibition of umbilical uptake within groups of amino acids. Am J Physiol Endocrinol Metab. 2004; 286(3): E376-E383

33. Constancia M, Hemberger M, Hughes J, Dean W, Ferguson-Smith A, Fundele R, et al. Placental-specific IGF-II is a major modulator of placental and fetal growth. Nature. 2002; 417(6892): 945-948.

34. Jansson N, Greenwood SL, Johansson BR, Powell TL, Jansson T. Leptin stimulates the activity of the system A amino acid transporter in human placental villous fragments. J Clin Endocrinol Metab. 2003; 88(3): 1205-1211.

35. Pappa KI, Vlachos G, Theodora M, Roubelakj M, Angelidou K, Antsaklis A. Intermediate metabolism in association with the amino acid profile during the third trimester of normal pregnancy and dietcontrolled gestational diabetes. Am J Obstet Gynecol. 2007; 196(1) 65.e1-5

36. Freyse EJ, Fischer U, Albrecht G, Salzsieder E. Alterations in alanine metabolism in diabetic dogs during short-term treatment with an artificial B cell. Diabetologia. 1985; 28(10): 763-768

37. Meynial-Denis D, Chavaroux A, Foucat L, Mignon M, Prugnaud J, Bayle $\mathrm{G}$, et al. Contribution of proteolysis and de novo synthesis to alanine production in diabetic rat skeletal muscle: a $15 \mathrm{~N} / 1 \mathrm{H}$ nuclear magnetic resonance study. Diabetologia. 1997; 40(10): 1159-1165.

38. Porcellati F, Pampanelli S, Rossetti P, Busciantella Ricci N, Marzotti S Lucidi $\mathrm{P}$, et al. Effect of the amino acid alanine on glucagon secretion in non-diabetic and type 1 diabetic subjects during hyperinsulinaemic euglycaemia, hypoglycaemia and post-hypoglycaemic hyperglycaemia. Diabetologia. 2007; 50(2): 422-430.

39. Lee CC, Watkins SM, Lorenzo C, Wagenknecht LE, Il'vasova D, Chen YI, et al. Branched-Chain Amino Acids and Insulin Metabolism: The Insulin Resistance Atherosclerosis Study (IRAS). Diabetes Care. 2016 Eepub ahead of print.

40. Reece EA, Coustan DR, Sherwin RS, Tuck S, Bates S, O'Connor $\mathrm{T}$, Tamborlane WV. Does intensive glycemic control in diabetic pregnancies result in normalization of other metabolic fuels? Am Obstet Gynecol. 1991; 165(1): 126-130.

41. Jóźwik M, Teng C, Wilkening RB, Meschia G, Tooze J, Chung M, Battaglia FC. Effects of branched-chain amino acids on placental amino acid transfer and insulin and glucagon release in the ovine fetus. Am J Obstet Gynecol. 2001; 185(2): 487-495.

42. Garcia RF, Gazola VA, Barrena HC, Hartmann EM, Berti J, Toyama $\mathrm{MH}$, et al. Blood amino acids concentration during insulin induced hypoglycemia in rats: the role of alanine and glutamine in glucose recovery. Amino Acids, 2007; 33(1): 151-155.

43. Reimann F, Williams L, da Silva Xavier G, Rutter GA, Gribble FM. Glutamine potently stimulates glucagon-like peptide-1 secretion from GLUTag cells. Diabetologia. 2004; 47(9): 1592-1601.

44. Franconi F, Loizzo A, Ghirlanda G, Seghieri G. Taurine supplementation and diabetes mellitus. Curr Opin Clin Nutr Metab Care. 2006; 9(1) $32-36$ 
45. Camelo Jr JS, Martinez FE, Gonçalves AL, Monteiro JP, Jorge SM. Plasma amino acids in pregnancy, placental intervillous space and preterm newborn infants. Braz J Med Biol Res. 2007; 40(7): 971-977.

46. Hay WW Jr. Placental transport of nutrients to the fetus. Horm Res. 1994; 42(4-5): 215-222.

47. McBride KL, Belmont JW, O'Brien WE, Amin TJ, Carter S, Lee BH. Heritability of plasma amino acid levels in different nutritional states. Mol Genet Metab. 2007; 90(2): 217-220.

48. Shikata N, Maki Y, Noguchi Y, Moru M, Hanai T, Takahashi M, Okamoto M. Multi-layered network structure of amino acid (AA) metabolism characterized by each essential AA-deficient condition. Amino Acids. 2007; 33(1): 113-121.

49. Haase TN, Rasmussen M, Jaksch CA, Gaarn LW, Petersen CK, Billestrup $\mathrm{N}$, Nielsen JH. Growth arrest specific protein (GAS) 6: a role in the regulation of proliferation and functional capacity of the perinatal rat beta cell. Diabetologia. 2013; 56(4): 763-773.

50. Duggleby SL, Jackson AA. Protein amino acid and nitrogen metabolism during pregnancy: how might the mother meet the needs of her fetus? Curr Opin Clin Nutr Metab Care. 2002; 5(5): 503-509.

51. Robinson S, Prendergast CH. Protein metabolism in pregnancy. Baillieres Clin Endocrinol Metab. 1996; 10(4): 571-587. 